\title{
Are Women More Empathetic than Men? A Longitudinal Study in Adolescence
}

\author{
María Vicenta Mestre, Paula Samper, María Dolores Frías, and Ana María Tur \\ Universidad de Valencia (Spain)
}

\begin{abstract}
Since the 1970s there has been a growing interest in analysing sex differences in psychological variables. Empirical studies and meta- analyses have contributed evidence on the differences between male and female individuals. More recently, the gender similarities hypothesis has supported the similarity of men and women in most psychological variables. This study contributes information on women's greater empathic disposition in comparison with men by means of a longitudinal design in an adolescent population. 505 male and female adolescents aged between 13 and 16 years were evaluated at two different moments (grade 2 and grade 3, lower secondary education). They completed the Index of Empathy for Children and Adolescents by Bryant and the Interpersonal Reactivity Index by Davis. The results confirm a greater empathic response in females than in males of the same age, differences growing with age. The sizes of the effect estimated in the second evaluation (average age 14 years) are large for emotional empathy and medium for cognitive empathy.
\end{abstract}

Keywords: empathy, gender differences, adolescence

Desde la década de los 70 se incrementa el interés por analizar las diferencias de género en las variables psicológicas y se publican estudios empíricos y trabajos de meta-análisis que aportan evidencia de las diferencias entre varones y mujeres. Más recientemente se ha planteado la hipótesis de la similitud de género que defiende la semejanza entre varones y mujeres en la mayoría de los constructos psicológicos. Este estudio aporta datos sobre la mayor disposición empática en la mujer respecto al varón a través de un diseño longitudinal en población adolescente. 505 adolescentes varones y mujeres, con un rango de edad entre 13 y 16 años fueron evaluados en dos momentos temporales ( $2^{\circ}$ y $3^{\circ}$ curso de ESO). Cumplimentaron el Índice de Empatía de Bryant y el Índice de Reactividad Interpersonal de Davis. Los resultados confirman mayor respuesta empática en las adolescentes respecto a los varones de su misma edad y constatan que dichas diferencias aumentan con la edad. Los tamaños del efecto estimados en el segundo momento (edad media 14 años) son grandes en la empatía emocional y medios en la cognitiva.

Palabras clave: empatía, diferencias de género, adolescencia

Correspondence concerning this article should be addressed to María Vicenta Mestre Escrivá, Departamento de Psicología Básica. Facultad de Psicología, Universidad de Valencia, Avda. Blasco Ibáñez, 21, 46010 Valencia, Spain. Phone: +34 9638648 22. E-mail: Maria.V.Mestre@uv.es

How to cite the authors of this article: Mestre, M.V, Samper, P., Frías, M.D., Tur, A.M. 
Systematic attempts to reach conclusions about sex differences and similarities became important in the 1970s in psychology. The book by E. E. Maccoby and C.N. Jacklin, The Psychology of Sex Differences (1974), is considered by psychologists to be the greatest effort ever made in summarising all sex comparisons carried out by psychological research (Eagly, 1995). The authors posed a number of questions: Are both sexes different as to their emotional response to people and events? Is their strength to cope with problems different? Are such differences unavoidable or the result of arbitrary social stereotypes that could change if society changed? Their review of almost 1,400 papers on sex differences in psychological variables allowed them to conclude that well grounded sex differences point to women's greater communication skills versus men's better visual-spatial and mathematical ability and greater physical and verbal aggression. In contrast, results were ambiguous in many other variables such as fear, anxiety, competitiveness, control-submission, and also empathy and the will to help others. With regard to the latter two variables, findings on altruism displayed gender similarities (Maccoby \& Jacklin, 1974). On the other hand, in his review of the subject, Hoffman (1977) differentiated between measures of empathy defined as an emotional response to the others' affective condition, and perspective taking and social sensitivity measures, concluding that women were more empathetic than men. In 1983, a comprehensive review published by Eisenberg and Lennon on sex differences in the tendency to be empathetic found sex differences in favour of women, empathy being also understood from the emotional and cognitive perspective and comparing different instruments. Yet, the authors pointed out that research remained open, "to date, the only thing that can be concluded with confidence is that many important issues concerning sex differences in emotional empathy are, as yet, unresolved" (Eisenberg \& Lennon, 1983, p. 126).

In Davis's multidimensional approach to empathy measurement, which measures cognitive and emotional factors as components of empathic disposition, the author concludes that significant sex differences exist for each individual scale in his instrument (Interpersonal Reactivity Index, IRI), women always scoring higher (Davis, 1983).

In 1990, after comparing his findings from 1974 and those of subsequent studies, Maccoby concluded again that results remained inconsistent in the personality and social behaviour field. Some studies described men as being more aggressive than women, while other studies considered men to be more altruistic, and other studies showed women to be more prone to be influenced by others. Maccoby adopted a social perspective in order to justify these sex differences, arguing that men and women are actually far more similar and that their lives are basically marked by features shared by everybody in a specific culture. In Maccoby's opinion, social behaviour should never be considered solely on the basis of the individual but should be considered as an interaction between two or more people, since people behave differently with different individuals (Maccoby, 1990).

Over the past decade interest has grown in empirically exploring the role of empathy in moral and prosocial behaviour and as an inhibitor of aggression and antisocial behaviour. In that context, Eisenberg reviewed the relevance of emotions and regulation in moral development, concluding that empathy as a regulated emotion targeted at others motivates prosocial behaviour, establishing links between emotional regulation and morality. In contrast, negative emotion and a poor self-regulation capacity are connected to maladapted behaviour and the externalisation of problems (Eisenberg, 2000). Studies completed with Spanish adolescent populations confirm the positive effect of empathy on social behaviour, empathy being described as a nonimpulsive emotion oriented towards the other, while emotional instability reaches the highest predictive power for aggressive and antisocial behaviour. In all these studies gender is a relevant moderating factor for these behaviours (Calvo, González, \& Martorell, 2001; Mestre, Samper, \& Frías, 2002; Sobral, Romero, Luengo, \& Marzoa, 2000).

Along the same lines, studies on adolescents have pointed to the relationship between high empathy and high altruism, this connection being stronger in girls than in boys (Carlo, Hausmann, Christiansen, \& Randall, 2003). These results are confirmed if processes are not simply analysed on the basis of gender but if the orientation of the gender role is also evaluated. Thus, a female orientation is predictive of greater empathy both as concern for the other and as perspective taking (Carlo, Koller, Eisenberg, Silva, \& Frohlich, 1996; Eisenberg, Zhou, \& Koller, 2001) and predictive of less criminal behaviours in adolescents with this type of orientation (Keung Ma, 2005).

Furthermore, empathy is also significantly related to maladapted behaviours in young people, becoming a strong predictor of antisocial behaviour in both boys and girls, but the emotional component is the greatest protection factor for women (Broidy, Cauffman, Espelage, Mazerolle, \& Piquero, 2003). In other studies, empathy is associated with less negative reactions to insults especially in males when compared to females (Toussaint \& Webb, 2005). The interaction between empathy and gender in the prediction of prosocial behaviour shows a strong link between empathy and prosocial behaviour in males (McMahon, Wernsman, \& Parnes, 2006).

Lastly, current research focuses on identifying interactions between personal and contextual factors, and within these contextual factors research on parenting styles is a particular interest. Thus, parenting styles characterised by affection, control and emotional support seem to boost empathy and prosocial development, while hostile and rigid styles marked by a negative evaluation of the child facilitates aggression. When such interactions are analysed from the perspective of sex differences, girls seem to be more receptive to affection and support in family relationships (Carlo, Raffaelli, 
Laible, \& Meyer, 1999; Mestre, Samper, \& Frías, 2004; Mestre, Samper, Tur, Cortés, \& Nácher, 2006).

Although the studies repetitively confirm the important regulating role of empathy in prosocial behaviour and its inhibitory power on aggressive and antisocial behaviours, gender plays a moderating role. The findings suggest that the question of sex differences in empathy and social behaviours remains unresolved and that research on prosocial behaviour and potential moderating variables must consider sex differences. Further research on this issue is needed to examine the gender similarities hypothesis (Hyde, 2005). This hypothesis suggest that men and women are similar in most -not all- psychological variables. As far as helping behaviour is concerned, Hyde's meta-analytic review of 46 studies showed that differences in favour of men (situations of greater danger) can be either large or close to zero depending on the social environment where the behaviour was measured. Therefore, the issue of sex differences in prosocial behaviours is unclear. Rather, further empirical evidence is needed to investigate sex differences in empathy, prosocial behaviour and aggression.

Based on the gender similarities hypothesis on the one hand and the empirical studies and reviews of recent decades on the other, we decided to undertake this study to examine differences or similarities between male and female adolescents in empathy-related cognitive and emotional processes, given the important role that it plays in adaptive or maladaptive behaviour in youth. The findings will inform educational programmer aimed at promoting empathy and prosocial behaviours as inhibitors of aggressive behaviours.

Using a longitudinal design, the following hypotheses were developed:

1. Female adolescents are more empathetic than their male peers with regard to both the cognitive components of empathy and the emotional ones.

2. Sex differences in empathy increase with age.

\section{Method}

\section{Participants}

The sample consisted of 505 subjects randomly selected from state schools (30.3\%) and partly subsidised ones (69.7) from the Valencia region (Spain), their ages ranging from
13 to 16 years ( 242 boys and 263 girls). The study included all classes from grade 2 (secondary education). In the first evaluation, the participants had a mean age of 13.25 years $(S D=0.460,13$ years minimum age and 15 years maximum age) and in the second one mean age was 14.25 years $(S D$ $=0.560,13$ years minimum age and 16 years maximum age). In the first evaluation phase (academic year 20022003), subjects were in year 2, lower secondary, and in year 3 in the second phase.

\section{Instruments}

All subjects filled in the following empathy questionnaires, adapted to the Spanish population:

Index of Empathy for Children and Adolescents (IECA; Bryant, 1982). This index is intended to measure empathy in different situations with emotional connotations, an individual of the same or opposite sex being the character of the scene/item and also including neutral statements where empathy is expressed without a gender reference. It measures the emotional component of empathy. It consists of 22 items: Four with a female reference, four with a male reference and 14 without a specific reference. Answers were dichotomous (yes or no), high scores reflecting high empathy. The internal consistency analysis of Bryant's instrument (1982) showed a Cronbach's alpha of 0.67, this value was higher with age. In our study (Mestre, Pérez-Delgado, Frías, \& Samper, 1999), the Cronbach's alpha reliability coefficients obtained for the sample at the two evaluation moments were 0.75 for Evaluation 1 and 0.77 in Evaluation 2.

Interpersonal Reactivity Index (IRI; Davis, 1980). This instrument evaluates empathetic disposition by means of two emotional factors and two cognitive ones: Perspective Taking, Fantasy, Empathic Concern, and Personal Distress. It includes 28 Likert-type items with five possible options scoring 1 to 5. The reliability analysis of the IR empathy questionnaire included the calculation of Cronbach's alpha for the four subscales in the instrument. Other studies with Spanish adolescent populations have obtained similar coefficients (Mestre et al., 1999; Mestre, Frías, \& Samper, 2004, Mestre, Samper, Tur, Díez, \& Nácher, 2001-2004) (see Table 1). Alpha values for the present sample ranged between 0.55 for the Personal Distress (PD) scale in evaluation 1 and 0.68 for the Fantasy (FS) scale in evaluation 2 (see Table 1).

Table 1

Reliability coefficients of Interpersonal Reactivity Index subscale in evaluation 1 and evaluation 2

\begin{tabular}{lcccccc}
\hline & Items & Evaluation 1 & Evaluation 2 & Mestre, et al (1999) & Mestre et al (2001-2004) & Mestre et al (2004) \\
\hline PT & 7 items & 0.61 & 0.64 & 0.64 & 0.63 & 0.56 \\
FS & 7 items & 0.64 & 0.68 & 0.75 & 0.68 & 0.70 \\
EC & 7 items & 0.62 & 0.62 & 0.58 & 0.64 & 0.65 \\
PD & 7 items & 0.55 & 0.65 & 0.69 & 0.64 & 0.64 \\
\hline
\end{tabular}




\section{Procedure}

In the first evaluation, secondary education schools were randomly selected. A total of 22 schools and 36 classes participated. All the groups in the corresponding level (Year 2 and Year 3) were assessed. In the research design, two successive evaluations of the same student groups were conducted in the first term of the school calendar, one evaluation per year.

Subjects were evaluated in groups and at school hours at the classroom. Verbal instructions were given before filling in the questionnaires. They were administered in a $45 \mathrm{~min}$ session (approximately) in the two evaluations.

\section{Results}

The approach of the research hypothesis requires exploring the effect of interactions between gender and chronological age. In our hypothesis women, were expected to be more empathetic than men, these differences were expected to increase with age. The study of the effect of the interaction gender/chronological age was based on a mixed design with two factors, sex (boy-girl) and chronological age (Moment 1-Moment 2). The chronological age was operationalized as two assessment period separated by a one-year interval, as explained in the sample description. At Moment 1, subjects were 13.25 years old on average and at Moment 2, the mean age was 14.25 years. Each individual variable measured with either the scales or the subscales were analysed on the basis of this design type.

Results from the analysis of variance using the mixed design between sex and chronological age show a statistically significant interaction effect with each measuring instrument (see Table 2). The analysis of variance shows the equality of variances $(p>.05)$ in the mixed designs of each one of the subscales of empathy, both in the main and interaction effects. The fulfilment of the esfericity of covariances matrixes is not an obstacle in our design provided that only two groups are in each variable in our repeated measures design. The mean scores and standard deviations of the interaction effects between sex and chronological age can be seen in Table 3 .

Figure 1 and Figure 2 show the interactions between sex and chronological age, for each measure used. The graphic representations of the interactions are positive ordinal, the girls' mean score always being higher than that of boys,

Table 2

Results of the effect of interaction between Sex and Chronological Age in the mixed design

\begin{tabular}{|c|c|c|c|}
\hline Instrument & $F$ value & $p$ & $\eta_{p}^{2}$ \\
\hline Index of empathy for children and adolescents (IECA) & $F_{(1,503)}=6.461$ & 0.011 & 0.013 \\
\hline Perspective taking $(P T)$ & $F_{(1,502)}=5.967$ & 0.015 & 0.012 \\
\hline Fantasy $(F S)$ & $F_{(1,502)}=20.674$ & 0.001 & 0.040 \\
\hline Emphatic concern $(E C)$ & $F_{(1,503)}=38.222$ & 0.001 & 0.071 \\
\hline Personal distress $(P D)$ & $F_{(1,502)}=24.236$ & 0.001 & 0.046 \\
\hline
\end{tabular}

Table 3

Measure of Sex $\times$ Chronological Age interaction and standard deviation

\begin{tabular}{lcccc}
\hline \multirow{2}{*}{ Instrument } & \multicolumn{2}{c}{ Boys } & \multicolumn{2}{c}{ Girls } \\
\cline { 2 - 5 } & Evaluation 1 & Evaluation 2 & Evaluation 1 & Evaluation 2 \\
\hline \multirow{2}{*}{ IECA } & 13,566 & 13,562 & 17,308 & 17,939 \\
& $(3,22)$ & $(2,816)$ & $(3,227)$ & $(2,822)$ \\
PT & 16,062 & 21,901 & 17,233 & 24,164 \\
& $(4,216)$ & $(4,59)$ & $(4,21)$ & $(4,581)$ \\
FS & 13,227 & 19,483 & 14,263 & 22,679 \\
& $(4,962)$ & $(5,46)$ & $(4,97)$ & $(5,455)$ \\
EC & 11,450 & 22,942 & 12,298 & 26,378 \\
& $(3,873)$ & $(4,091)$ & $(3,87)$ & $(4,095)$ \\
PD & 13,384 & 16,459 & 14,092 & 19,321 \\
& $(4,03)$ & $(4,558)$ & $(4,03)$ & $(4,548)$ \\
\hline
\end{tabular}

* Standard deviation in brackets. 
both in Year 1 and Year 2 of the evaluation. In addition, the positive nature of the interaction effects shows that at Moment 2, differences between the mean scores of boys and girls increase if compared to Moment 1 . The statistical

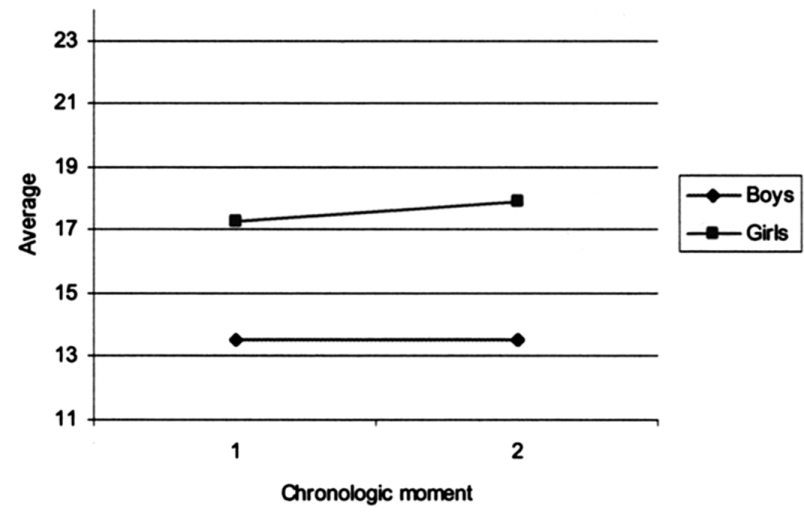

Figure 1. Graphic representation of mean values of interaction between Sex $\times$ Chronological Development in Bryant's IECA.

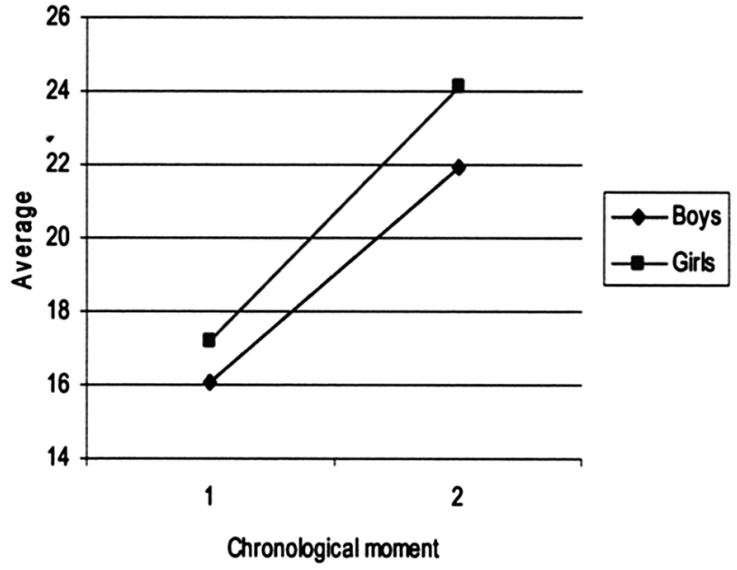

EC

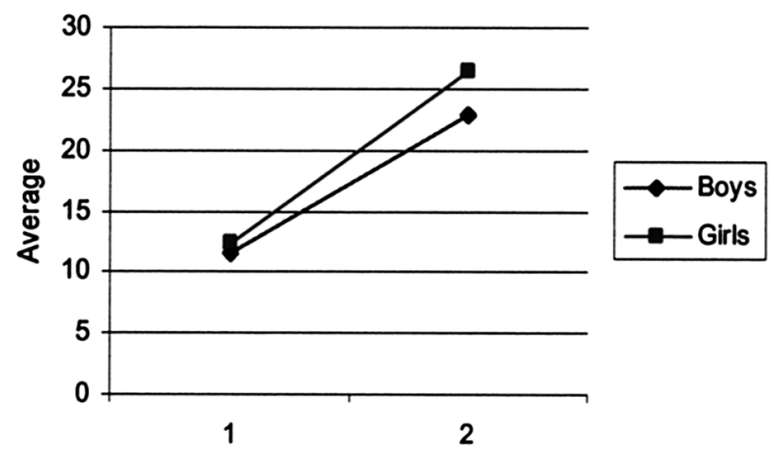

Chronological moment study of the interaction effect between sex and chronological age was conducted with the Bonferroni correction for multiple comparisons.

With regard to main effects of sex at age assessment period, several significant differences in empathy between boys and girls were found. In Bryant's scale, statistically significant differences in means between boys and girls were found at Moment 1, with a mean difference of 3.742, $p=$ .001 , and at Moment 2 with a mean difference of $4.377, p$ $=.001$, the girls' mean score always higher than that of boys in each assessment period.

All subscales in the IRI show that mean scores for both sexes increase with age but the girls' higher mean values remain, an increase in the sex differences occurring in Evaluation 2 The ordinal effect is seen in the Perspective Taking subscale, girls obtaining a higher mean value in each assessment period. Differences with boys are statistically significant for both Evaluation 1 (mean value difference $1.171, p=.002$ ) and Evaluation 2 (mean value difference $2.263, p=.001)$.

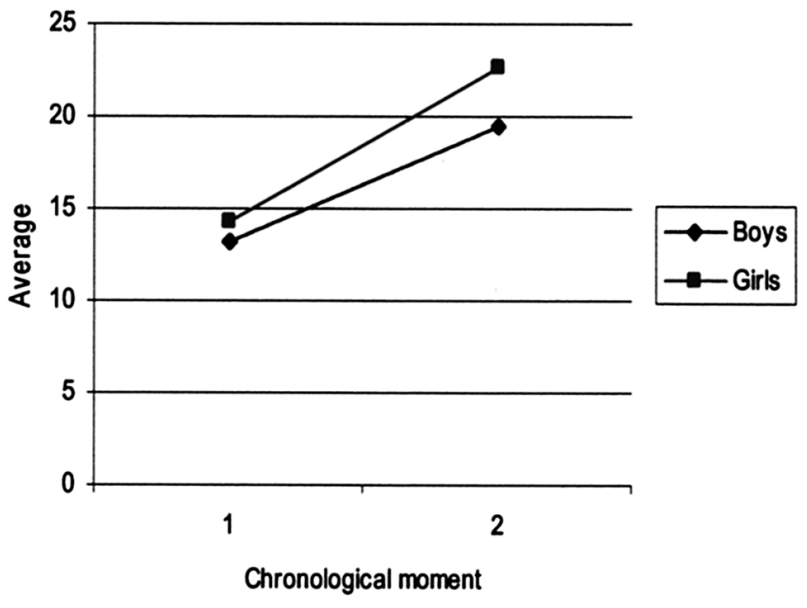

PD

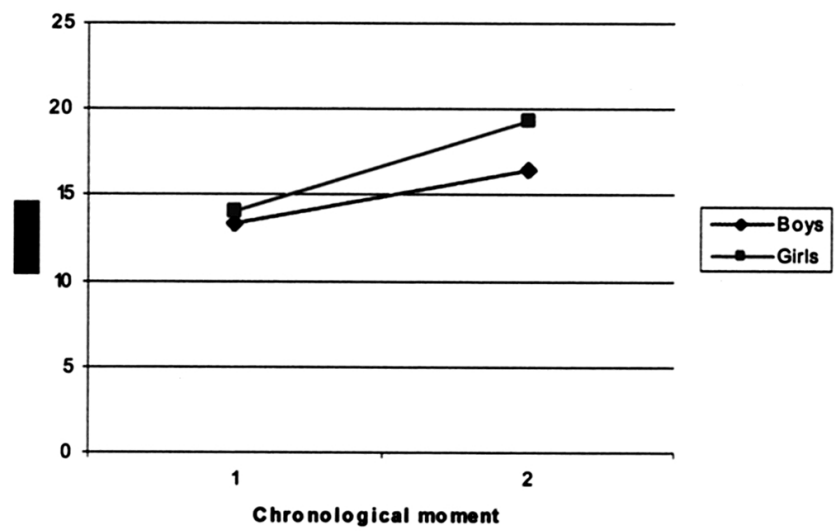

Figure 2. Graphic representation of mean values of interaction between Sex $\times$ Chronological Development in Davis's Interpersonal Reactivity Index subescales 
Similarly, in the Fantasy subscale girls obtain a higher mean value in each assessment period. Differences with boys are statistically significant for both Evaluation 1 (mean value difference 1.036, $p=.02$ ) and Evaluation 2 (mean value difference $3.196, p=.001$ ).

The ordinal interaction effect is identified in the Emphatic Concern subscale, girls obtaining a higher mean value in each assessment period. Differences with boys are statistically ignificant for both Moment 1 (mean value difference $0.847, p=.014$ ) and Moment 2 (mean value difference $3.436, p=.001$ ).

In the Personal Distress subscale, girls obtain a higher mean value in each assessment period. Differences with boys are statistically significant for both Moment 1 (mean value difference 0.707, $p=.05$ ) and Moment 2 (mean value difference $2.862, p=.001$ ).

The sizes of the effect of the standardised means differences $(d)$ identified by Bryant's IECA are large in Cohen's (1988) terms in both the first $(d=1.161)$ and second evaluation $(d=1.552)$ (see Table 4$)$. Davis's IRI instrument shows that in the first evaluation the size of the effect is small, around 0.2. However, in the second evaluation, the size of the effect grows to 0.5 approximately in Cohen's terms, emotional empathy measured by the Empathic Concern subscale (EC) reaching a large effect size $(d=0.84)$.

Therefore, the estimations of the effect sizes obtained by Cohen's $d$ concerning empathy levels in boys and girls are higher in the second evaluation if compared to those of the first assessment.

\section{Discussion}

Based on the findings, we can conclude that there are statistically significant differences between same age, male and female adolescents as far as their ability to feel or experience the emotions of others are concerned (emotional empathy) and in their cognitive capacity to understand the others' emotions (cognitive empathy). Furthermore, sex differences in empathy increased considerably between the first and the second assessment period. Same age girls are therefore more empathetic than boys and sex differences are greater (larger effect size) as they move on to the following developmental stage.

The two developmental moments chosen for the present study are the key to understanding sex differences in empathy. Turning 14 years of age entailed greater differences between boys and girls, as shown by the results. The changes in sex differences between boys and girls were identified in both Bryant's IECA -which just evaluates the emotional component of empathy- and Davis's IRI, where empathy is measured from a multidimensional perspective including both cognitive and emotional aspects of the empathic response. Understanding those changes and the sex differences is fundamental to developing programmes that focus on empathy development.

Although sex differences were found in both the Bryant and Davis measures, the effect sizes were larger for emotional empathy than for cognitive empathy. Furthermore, there was a greater effect size in the IECA instrument than in the Empathic Concern subscale of the IRI. This result

Table 4

Effect sizes (d) and Confidence Interval (95\%) in boys and girls in evaluations 1 and 2

\begin{tabular}{|c|c|c|c|c|}
\hline \multirow{2}{*}{ Instrument } & \multicolumn{2}{|c|}{ Evaluation 1} & \multicolumn{2}{|c|}{ Evaluation 2} \\
\hline & Effect size & Confidence interval & Effect size & Confidence interval \\
\hline IECA & $\begin{array}{c}d=1,161 \\
(0.096)\end{array}$ & $\begin{array}{c}0.972-1.350 \\
p=0.000\end{array}$ & $\begin{array}{c}d=1,552 \\
(0.102)\end{array}$ & $\begin{array}{c}1.352-1.752 \\
p=0.000\end{array}$ \\
\hline PT & $\begin{array}{c}d=0.278 \\
(0.089)\end{array}$ & $\begin{array}{c}0.102-0.454 \\
p=0.002\end{array}$ & $\begin{array}{c}d=0,493 \\
(0.090)\end{array}$ & $\begin{array}{c}0.315-0.671 \\
p=0.000\end{array}$ \\
\hline FS & $\begin{array}{c}d=0.207 \\
(0.089)\end{array}$ & $\begin{array}{c}0.032-0.383 \\
p=0.020\end{array}$ & $\begin{array}{c}d=0.586 \\
(0.091)\end{array}$ & $\begin{array}{c}0.407-0.765 \\
p=0.000\end{array}$ \\
\hline $\mathrm{EC}$ & $\begin{array}{c}d=0.219 \\
(0.089)\end{array}$ & $\begin{array}{c}0.044-0.395 \\
p=0.014\end{array}$ & $\begin{array}{c}d=0.840 \\
(0.093)\end{array}$ & $\begin{array}{c}0.657-1.023 \\
p=0.000\end{array}$ \\
\hline PD & $\begin{array}{c}d=0.176 \\
(0.089)\end{array}$ & $\begin{array}{c}0.001-0.352 \\
p=0.048\end{array}$ & $\begin{array}{c}d=0.628 \\
(0.091)\end{array}$ & $\begin{array}{c}0.449-0.808 \\
p=0.000\end{array}$ \\
\hline
\end{tabular}

* Standard error of the effect size in brackets

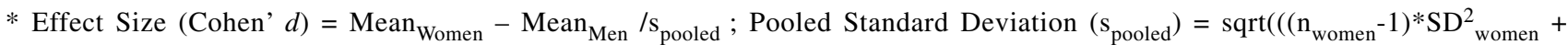
$\left.\left.\left(\mathrm{n}_{\text {men }}-1\right) * \mathrm{SD}_{\text {men }}^{2}\right) /\left(\mathrm{n}_{\text {women }}+\mathrm{n}_{\text {men }}-2\right)\right)$ 
reveals greater sensitivity in IECA for the evaluation of emotions related to the need of others for the studied age range. Thus, the findings suggest that empathy studies should be conducted in the early years of adolescence when the goals are to analyse changes in the emotional aspects of empathy.

Within each assessment period, girls scored higher than boys in their ability to stand in "the other person's shoes" and also in the feelings towards a person in trouble or in need. Therefore, sex differences are not just found in the emotional realm of empathy but also in the capacity of understanding the other person's state and situation. These findings are in line with those obtained by the instrument's author (Davis, 1983) and by other experts who have also used the IRI for empathy evaluation from a multidimensional perspective (Carlo et al., 2003; Carlo et al., 1996; Carlo et al., 1999; Eisenberg et al., 2001; Mestre et al, 2004; Mestre et al., 2002).

The effect sizes obtained illustrate the largest effect size being found when empathy was evaluated by Bryant's IECA. The effect size using Bryant measure is large at the two evaluation moments. In constrast, all the subscales in Davis's IRI showed a larger effect size at the second evaluation moment compared to the first evaluation moment, the effect size ranging between medium and large. The Empathic Concern factor had an especially large effect in the second evaluation. From the perspective of the gender similarities hypothesis, Hyde's review (2005) of studies on moral reasoning oriented towards care (the closest construct to empathy studied by the author) estimated an effect size of 0.28 (small effect size). In our analysis, effect size values remain at about 0.20 (except for IECA) in Moment 1 but they were larger in Moment 2, indicating that there were greater differences in empathy in later adolescence.

The implications of our empathy results are strongly in line with the study of prosocial behaviour and antisocial behaviour inhibition and bullying (Jolliffe \& Farrington, 2004, 2006), which also reveals sex differences. Thus, subjects with low empathy seem to have problems in relating their antisocial behaviour with emotional reactions in others, and men seem to be more likely to violently bully others in comparison with women (Olweus, 1993). The analysis of the links between these constructs will allow to reapproach differences between emotional and cognitive empathy, given the results that associate negative relationships between emotional empathy and bullying (Endresen \& Olweus, 2002) and between bullying and cognitive empathy (Sutton, Smith, \& Swettenham, 1999). In summary, empathic disposition, which is considered to be the main driver of prosocial behaviour, is developed in female adolescents to a greater extent than in male adolescents. This result should be taken into account in the design of educational programmes aimed at improving prosocial disposition and positive social interaction, and at inhibiting aggression. Now that violent behaviours have became more frequent in different settings, empathy development, in its cognitive (perspective taking) and emotional (concern for the other) aspects, can play an inhibiting role and become a protective factor within the family and in school. Research must further find statistically significant interaction effects that can help us identify the variables that moderate prosocial and aggressive behaviours, the form they take on in male and female individuals, and the effects that the development of a higher empathy level has on both males and females.

\section{References}

Broidy, L., Cauffman, E., Espelage, D. L., Mazerolle, P., \& Piquero, A. (2003). Sex differences in empathy and its relation to juvenile offending. Violence and Victims, 18(5), 503-516

Bryant, B. K. (1982). An index of empathy for children and adolescents. Child Development, 53, 413-425.

Calvo, A. J., González, R., \& Martorell, M. C. (2001). Variables relacionadas con la conducta prosocial en la infancia y la adolescencia: personalidad, autoconcepto y género. Infancia y Aprendizaje, 93, 95-111.

Carlo, G., Hausmann, A., Christiansen, S., \& Randall, B. A. (2003). Sociocognitive and behavioural correlates of a measure of prosocial tendencies for adolescents. Journal of Early Adolescence, 23(1), 107-134

Carlo, G., Koller, S. H., Eisenberg, N., Silva, M. S., \& Frohlich, C. B. (1996). A cross-national study on the relations among prosocial moral reasoning, gender role orientations, and prosocial behaviours. Developmental Psychology, 32(2), 231240

Carlo, G., Raffaelli, M., Laible, D. J., \& Meyer, K. A. (1999). Why are girls less physically aggressive than boys? Personality and parenting mediators of physical aggression. Sex Roles, 40(9/10), 711-729

Cohen, J. (1988). Statistical power analysis for the behavioral sciences $\left(2^{\text {nd }}\right.$ ed). Hillsdale, NJ: Erlbaum. Davis, M. H. (1980). A multidimensional approach to individual differences in empathy. JSAS Catalog of Selected Documents in Psychology, 10,85

Davis, M. H. (1983). Measuring individual differences in empathy: Evidence for a multidimensional approach. Journal of Personality and Social Psychology, 44(1), 113-126

Eagly, A. H. (1995). The science and politics of comparing women and men. American Psychologist, 10(3), 145-158

Eisenberg, N. (2000). Emotion, regulation, and moral development. Annual Review of Psychology, 51, 665-697

Eisenberg, N., \& Lennon, R. (1983). Sex differences in empathy and related capacities. Psychological Bulletin, 94(1), 100-131

Eisenberg, N., Zhou, Q., \& Koller, S. (2001). Brazilian adolescents' prosocial moral judgment and behavior: relations to sympathy, perspective taking, gender-role orientation, and demographic characteristics. Child Development, 72(2), 518-534 
Endresen, I. M., \& Olweus, D. (2002). Self-reported empathy in Norwegian adolescents: sex differences, age trends and relationships to bullying. In D. Stipek \& A. Bohart (Eds.), Constructive and destructive behaviour: Implications for family, school and society (pp. 147-165). Washington, DC: American Psychological Association.

Hoffman, M. L. (1977). Sex differences in empathy and related behaviors. Psychological Bulletin, 54, 712-722

Hyde, J. S. (2005). The gender similarities hypothesis. American Psychologist, 60(6), 581-592.

Jolliffe, D., \& Farrington, D. P. (2004). Empathy and offending: a systematic review and meta-analysis. Aggressive and Violent Behaviour, 9, 441-476.

Jolliffe, D., \& Farrington, D. P. (2006). Examining the relationship between low empathy and bullying. Aggressive Behaviour, 32, 540-550.

Keung Ma, H. (2005). The relation of gender-role classifications to the prosocial and antisocial behaviour of Chinese adolescents. The Journal of Genetic Psychology, 166(2), 189-201.

Maccoby, E. E. (1990). Gender and relationships: A developmental account. American Psychologist, 45(4), 513-520).

Maccoby, E. E., \& Jacklin, C. N. (1974). The psychology of sex differences. Stanford, CA: Stanford University Press.

McMahon, S. D., Wernsman,, J., \& Parnes, A. L. (2006). Understanding prosocial behaviour: The impact of empathy and gender among African American adolescents. Journal of Adolescent Health, 39(1), 135-137

Mestre, V., Frías, M. D., \& Samper, P. (2004). La medida de la empatía: Análisis del Interpersonal Reactivity Index. Psicothema, 16(2), 255-260.

Mestre, V., Pérez-Delgado, E., Frías, M. D., \& Samper, P. (1999). Instrumentos de evaluación de la empatía. In E. Pérez-Delgado \& V. Mestre (Eds.), Psicología moral y crecimiento personal (pp.181-190). Barcelona: Ariel.
Mestre, V., Samper, P., \& Frías, M. D. (2002). Procesos cognitivos y emocionales predictores de la conducta prosocial y agresiva: La empatía como factor modulador. Psicothema, 14, (2), 227232

Mestre, V., Samper, P., \& Frías, M. D. (2004). Personalidad y contexto familiar como factores predoctores de la disposición prosocial y antisocial de los adolescentes. Revista Latinoamericana de Psicología, 36, 445-457

Mestre, V., Samper, P., Tur, A., Cortés, M. T., \& Nácher, M. J. (2006). Conducta prosocial y procesos psicológicos implicados: Un estudio longitudinal en la adolescencia. Revista Mexicana de Psicología, 23(2), 203-215.

Mestre, V., Samper, P., Tur, A., Díez, I., \& Nácher, M. J. (20012004). Estilos de crianza y variables escolares relacionadas con la conducta prosocial y la conducta agresiva: Un estudio longitudinal. R\&D\&I project, ref. BSO2001-304, Ministerio de Ciencia y Tecnología.

Olweus, D. (1993). Bullying at school. Oxford, England: Blackwell. Pérez-Albéniz, A., de Paúl, J., Etxebarría, J., Montes, M. P., \& Torres, E. (2003). Adaptación del Interpersonal Reactivity Index (IRI) al español. Psicothema, 15(2), 267-272.

Sobral, J., Romero, E., Luengo, A., \& Marzoa, J. (2000). Personalidad y conducta antisocial: Amplificadores individuales de los efectos contextuales. Psicothema, 12(4), 661-670

Sutton, J., Smith P. K., \& Swettenham, J. (1999). Social cognition and bullying: Social inadequacy or skilled manipulation. British Journal of Developmental Psychology, 17, 435-450.

Toussaint, L., \& Webb, J. R. (2005). Gender differences in the relationship between empathy and forgiveness. The Journal of Social Psycholohy, 145(6), 673-685.

Received November 27, 2006 Revision received July 7, 2008 Accepted September 9, 2008 